\title{
UNCLASSIFIED.
}

Report No. BMI-998

Metallurgy and Ceramics

(M-3679, 15th Ed.)

Contract No, W-7405-eng-92

\section{APPARATUS FOR VISUAL STUDY OF \\ CORROSION BY HOT WATER}

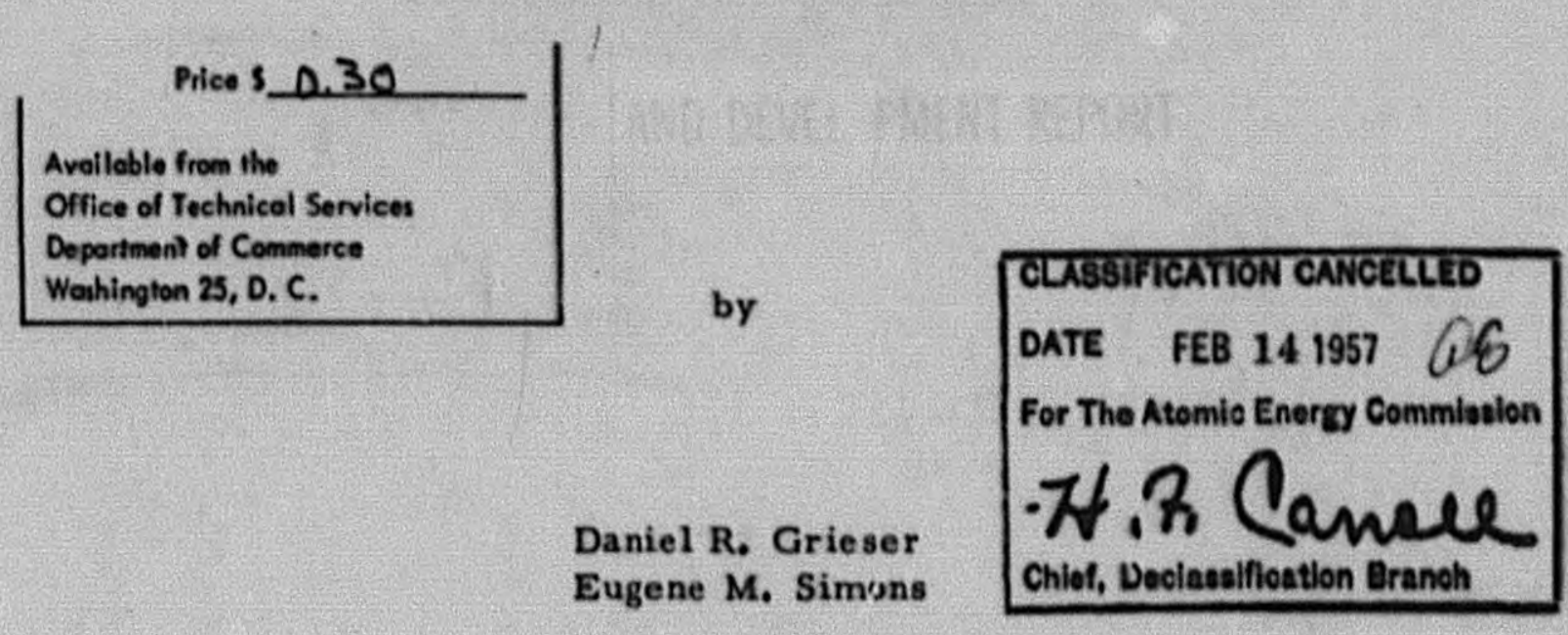

May 4, 1955

\section{LEGAL NOTICE}

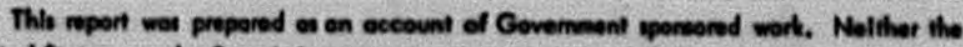

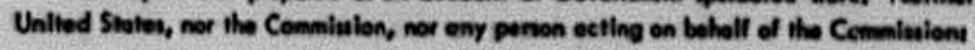

A. Maket any warronty of mpreventation, exprew or lmplied, with mapect to the ee-

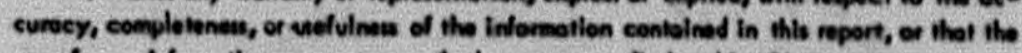
we of ony information, opporotu, method, or procen divelosed in this mport may not inIringe privatioly owned righty or

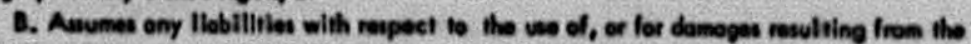
neo of any intomotion, apparctun, method, or procent divelosed in this report.

As uned in tho obove, "penon octing on betalf of the Comminion" includen any employee of controciot of the Commiluion to the extent that weh amployee of controctor

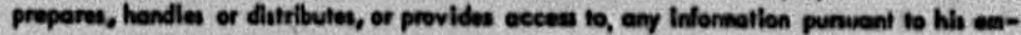
ployment or controct with the Comminion.

\section{BATTELLE MEMORLAL INSTITUTE}

505 King Avenue

Columbus 1, Ohin

\section{UNCLASSFFED}




\section{CONFIDENTLAL}

5 and 6

\section{TABLE OF CONTENTS}

\section{Page}

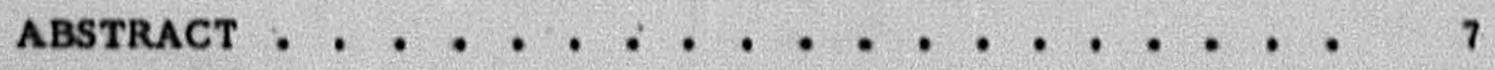

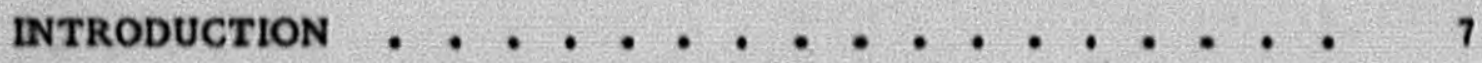

Apparatus . . . . . . . . . . . . . 8

The Viewing Autoclave . . . . . . . . . . 8

Specimen Mount . . . . . . . . . . . . 8

Preheat Autoclave and Pressure System . . . . . . 11

Camera Setup . . . . . . . . . . . . . 11

TEST PROCEDURE . . . . . . . . . . . . . . 14

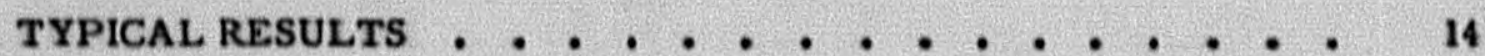

DISCUSSION . . . . . . . . . . . . . . 17 


\title{
APPARATUS FOR VISUAL STUDY OF CORROSION BY HOT WATER
}

by

\author{
Daniel R. Grieser and Eugene M. Simons
}

\begin{abstract}
The desige and operation of a uisdowed ausoclave switable for stwdying corrosion of asteriats by pressurixed bot water is described. Tbe tecbaique for taking tine-lapse motion pictures of a specianen from the instant of contact witb the bigb-temperatare water watil abe corrosion is complete is explained. A hpical set ol pictures is presented, sbouing the progress of the attack. Pressure and temperatare measureacats provide a means for nougb computatios of comosion rates. The results of sevenal tests of unclad and zircosiun-clad enbonded uranikn. zirconiva alloy cores subjected to pressarized bot water are presented. (ow 2 )
\end{abstract}

\section{INTRODUCTION}

Since uranium is oxidized by hot water with extreme rapidity, there has been concern over what might happen if a pinhole were to develop in the cladding of a uranium fuel element in service. If the corrosion were sudden and catastrophic, swelling could cause coolant-flow obstructions with possible progressive fuel-element burnout. Furthermore, radioactive fission products would be released into the coolant stream, making access for maintenance impractical until the activity had dropped to a tolerable level.

A windowed autoclave was designed and constructed to permit visual study of the reaction under conditions simulating a cladding failure in service. Although similar research is being done elsewhere, several features of the Battelle device are unique. One advantage is that the upper temperature is limited only by stresses in the pressure vessel, rather than by corrosive attack on the glass windows. Another is that the hot water can be made to contact the core suddenly, as would be the case if a flaw developed in the cladding of a fuel element in service. This provides a more interpretable test than the case where the specimen is subject to attack during the time the system is being heated and pressurized. 


\section{CONFIDENTUL}

\section{APPARATUS}

\section{The Viewing Autoclave}

Figure 1 shows a cross section of the autoclave. There are two windows; one for illumination and one for viewing. The se are mounted in the bottoms of water-cooled legs in order to permit cooling without introducing convection currents, which would distort the image.

The body of the pressure vessel is surrounded by eight Cromalox strip heaters, so arranged as to provide a slightly higher temperature at the top than at the bottom. This helps to insure that the image will not be distorted by convection currents or by rising steam bubbles. The heaters are surrounded by about $1 \mathrm{in}$, of thermal insulation. The temperature at the test specimen is maintained at the desired value by a controller which responds to a thermocouple located in the heating jacket. This method of control minimizes temperature cycling and accompanying pressure cycling.

All parts of the autoclave were machined from Type 304 stainless steel, with the exception of the copper window gaskers and cooling coils, the serrated nickel main gasket, the main thrust ring of oil-die steel, and the alloysteel set screws. Heliarc welding was used for all welded joints.

The Herculite glass windows were cemented to the window heads, using a thin coating of water-resistant adhesive. The neoprene O-rings were added to a standard Bridgman window seal, as shown, to permit the vessel to be evacuated without danger of dislodging the windows. These 0 -rings are not intended to seal, but merely to act as spacers. The seal is formed between the glass and the window head, as well as at the copper gasket.

The upper seal is a standard pressure closure, utilizing a serrated nickel gasket compressed between a closure head and the body of the pressure vessel. The thermocouple well, welded to the closure head, serves also to hold the specimen mount, thereby providing a convenient arrangement for inserting and removing specimens.

\section{$\underline{\text { Specimen Mount }}$}

The closure head with a pin-type test specimen mounted on the end of the thermocouple well is shown in Figure 2. The mounting permits sufficient rotating and sliding adjustments to position the specimen for maximum lighting and to center it along the axis of sight. Early trials with polished specimens gave images which showed only a narrow band of specularly reflected

CONFIDENTIAL

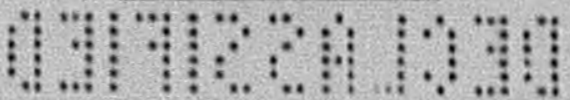




\section{$\frac{\text { CONFIDENTIAL }}{9}$}

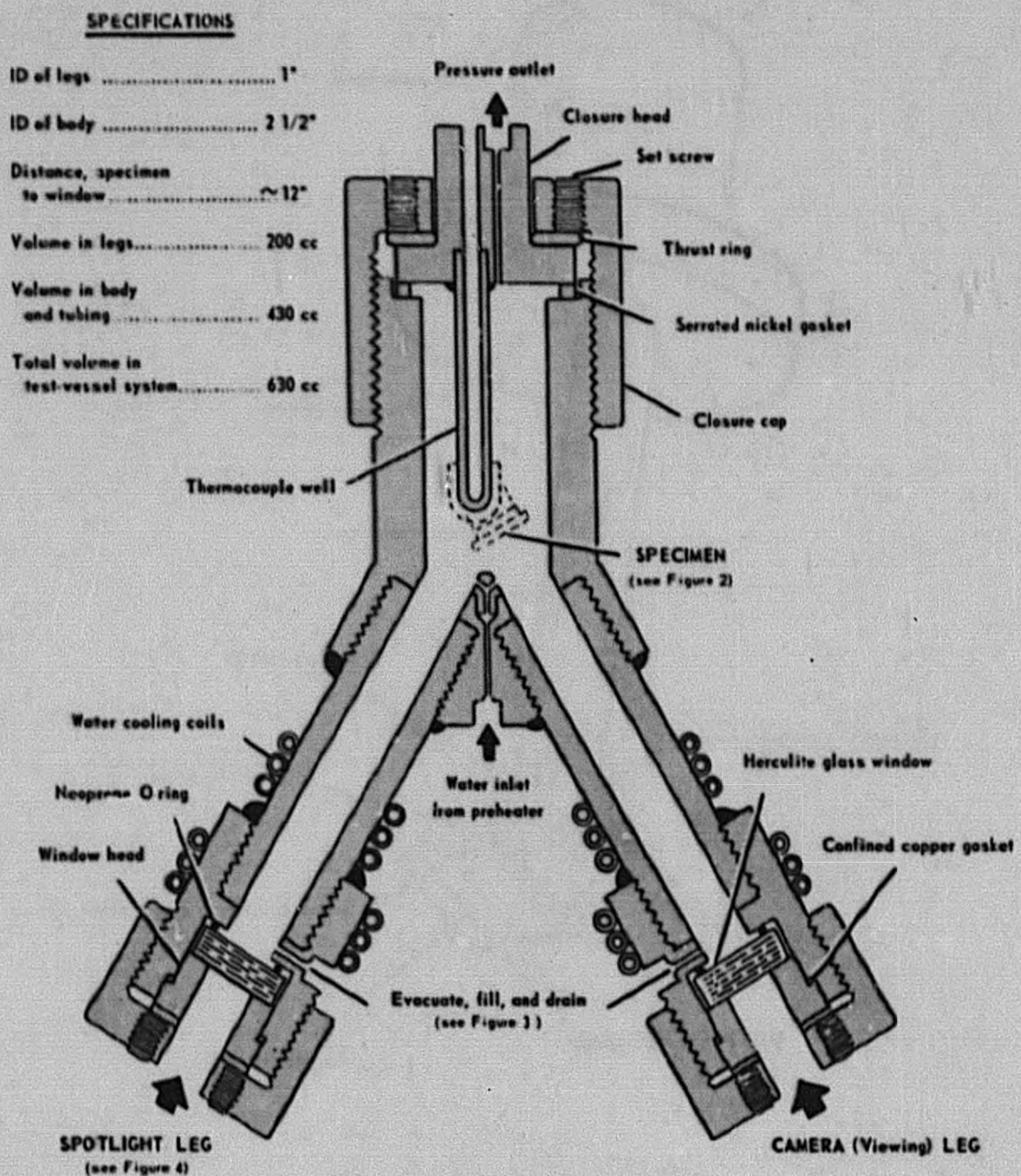

FIGURE I. CROSS SECTION OF IIINDOWED AUTOCLAVE 


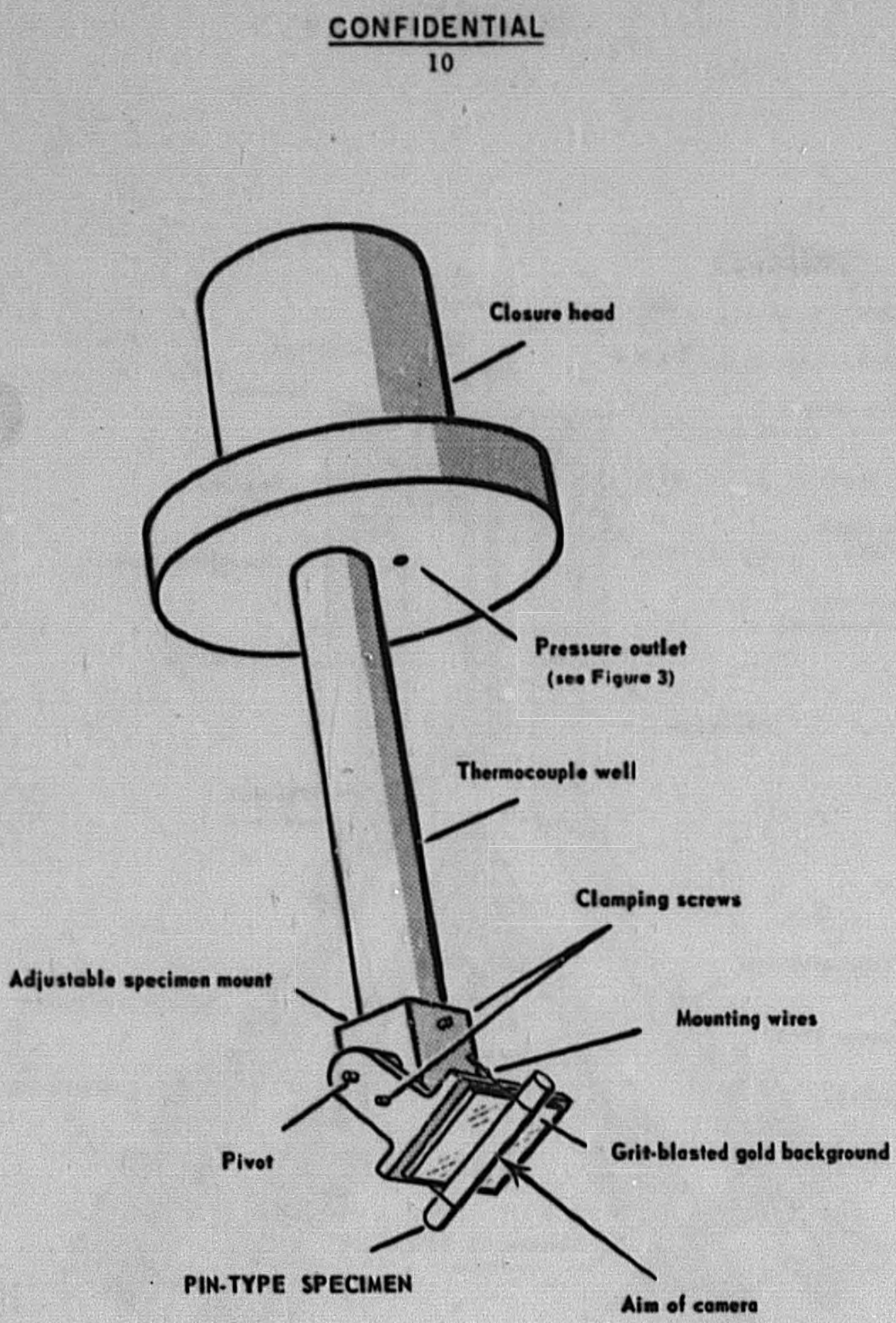

FIGURE 2. CLOSURE HEAD, FOR WINDOWED AUTOCLAVE, WITH SPECIMEN MOUNTED 


\section{CONFIDENTIAL}

light. This difficulty was remedied by using a frosted-gold background, as shown in Figure 2, and by putting a satin finish on the specimen with emery paper. The resulting image is much clearer, and the edges of the specimen are more sharply defined.

In cases where the specimen has a corrosion-resistant cladding, it is fastened to the mount with Nichrome wires as shown. Unclad specimens must be placed in a wire basket or in a stainless steel boat wired to the mount, in order to keep the specimen from falling into the cooled legs before the corrosion is complete. With unclad specimens, viewing is considerably more difficult and often impossible, because either the specimen container or the corrosion debris obscures the view.

\section{Preheat Autoclave and Pressure System}

Figure 3 is a diagram of the pressure system. The independently controlled $1000-\mathrm{cm}^{3}$ water-preheating autoclave is fitted with two outlets, one of which extends to the bottom of the vessel. It is thus possible to transfer the water to the previously heated test vessel as a liquid. The valving allows the legs of the test vessel and the preheat autoclave to be charged independently with predetermined amounts of water and then evacuated to outgas the water and remove air.

\section{Camera Setup}

Figure 4 is a sketch of the arrangement used to obtain time-lapse pictures of the specimen during the corrosion process. The light source illuminates a 1-in.-diameter circular area of specimen and background. The mirror at the end of the viewing leg is positioned so that the camera sees the specimen and the digital clock simultaneously. A beam-splitter is positioned in front of the camera lens so that a small fraction of the light is reflected at right angles to the photographic axis. This arrangement allows the operator to follow the progress of the corrosion visually without disturbing the picture taking. The camera used is a $16-\mathrm{mm}$ Paillard-Bolex, fitted with an external electric motor and spring drive and a 63-mm Ektanon Kodak lens. The time-lapse control and actuating solenoid is a Samenco movie control, capable of 1,2, 4, and 6 to 1,200-sec intervals between frames. 


\section{$\frac{\text { CONFIDENTIAL }}{12}$}

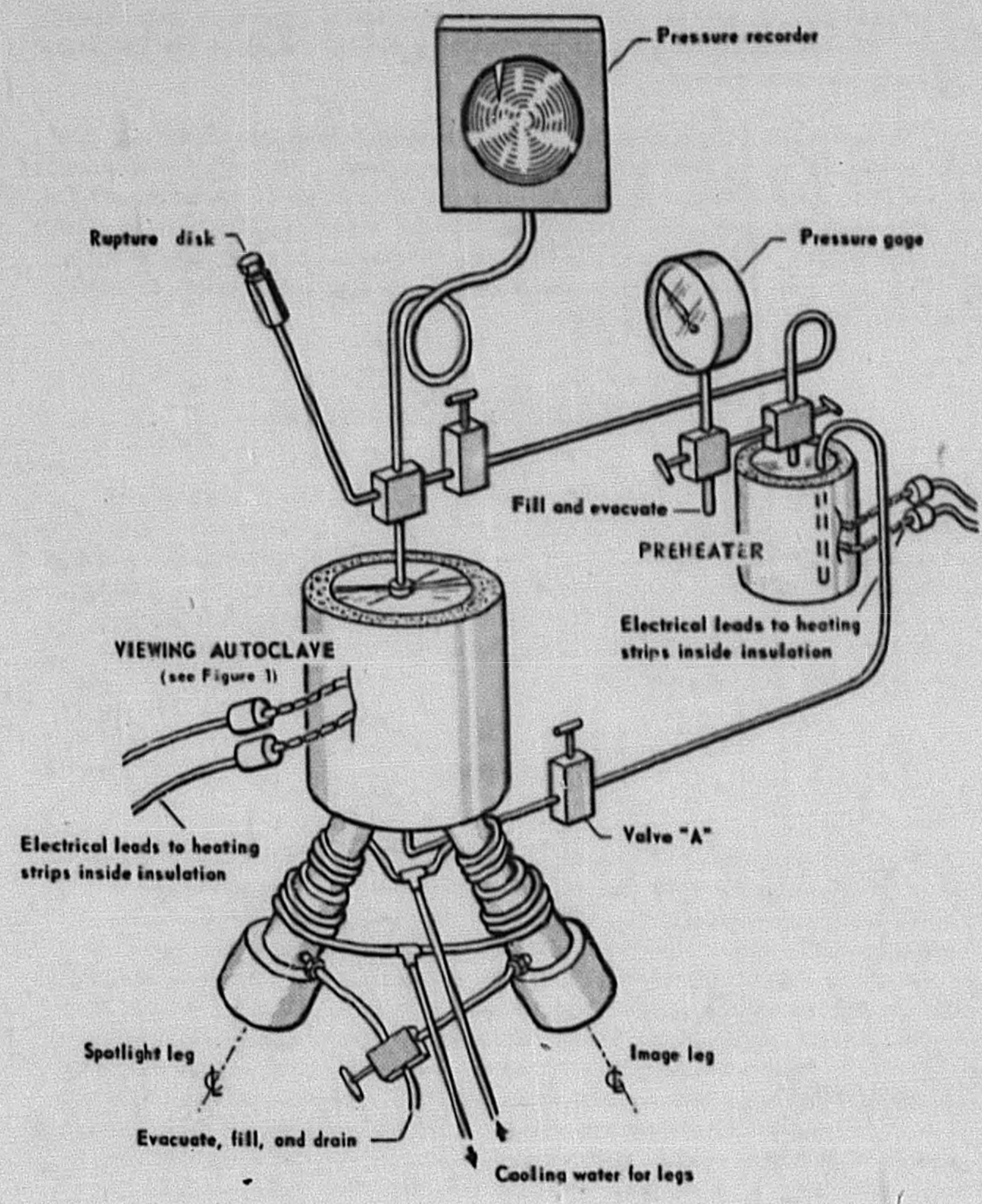

FIGURE 3. WINDOWED AUTOCLAVE SYSTEM 


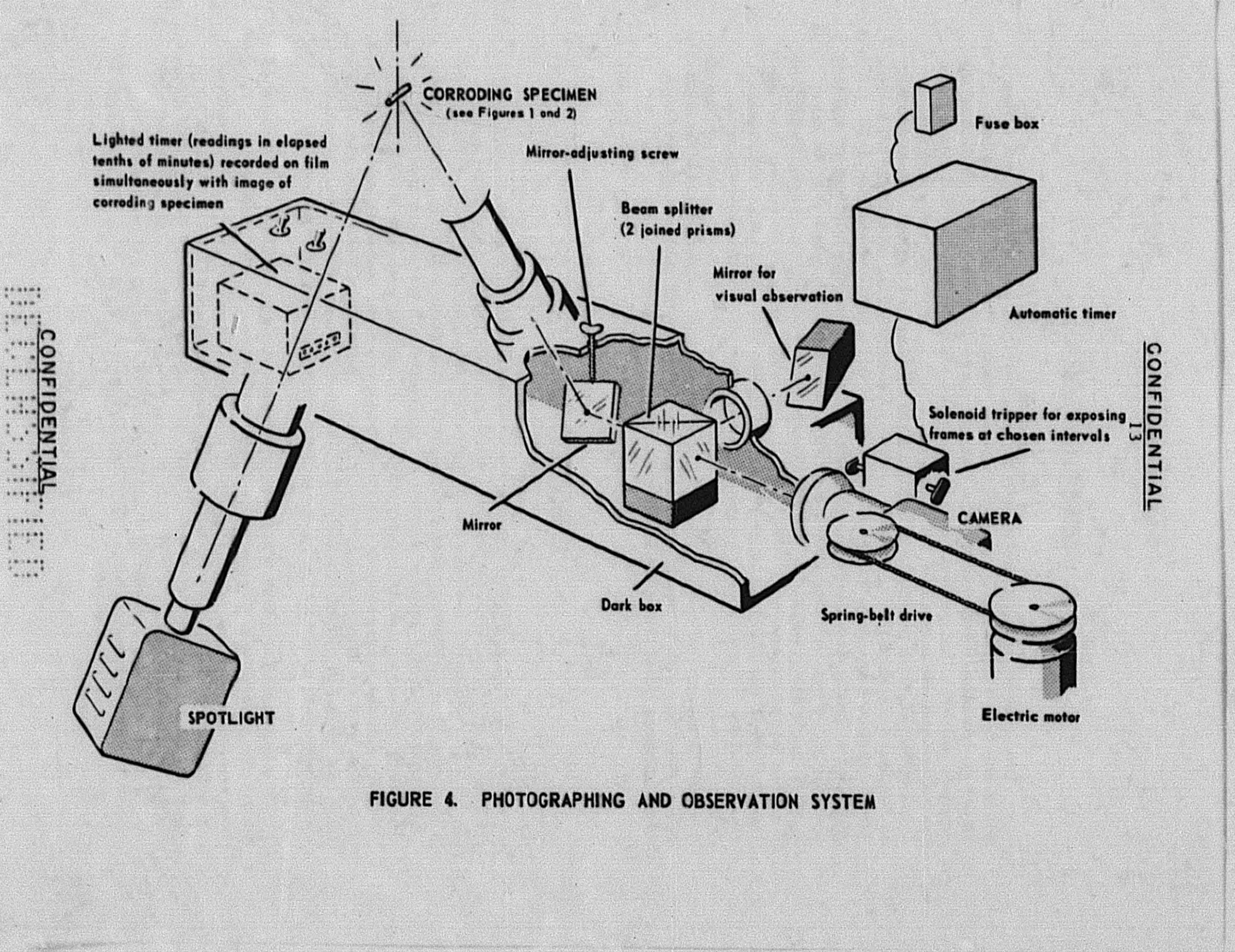




\section{CONFIDENTIAL}

14

\section{TEST PROCEDURE}

The specimen is prepared and mounted in the desired position, after which the test vessel is closed and sealed. Next, $100 \mathrm{~cm}^{3}$ of deionized water is introduced into the water-cooled legs to protect the glass during the preheat period. The preheat autoclave is loaded with $550 \mathrm{~cm}^{3}$ of water, and the entire system evacuated to outgas the water. With all valves in the system closed, the preheat and viewing autoclaves are heated independently to the test temperature. The test is initiated by turning on the pressure recorder and then opening Valve A (see Figure 3 ) to allow approximately $300 \mathrm{~cm}^{3}$ of preheated water to enter the viewing autoclave and engulf the test specimen. When working at $600 \mathrm{~F}$, this transfer is accomplished in less than $30 \mathrm{sec}$. The preheat vessel is then allowed to cool, as it has no further function in the experiment. Simultaneously with opening the valve, the timelapse control and the specimen and timer lights are turned on. From this time until the corrosion is complete, the operation is entirely automatic. When the test is over, the heaters and camera controls are turned off and the system is allowed to cool. The pressure record is continued until the system has cooled to room temperature. Then the quantity of water emptied from the windowed autoclave is measured.

\section{TYPICAL RESULTS}

A selection of four frames from an actual test has been reproduced in Figure 5. This particular pin-type specimen contained a uranium core welded to zirconium end plugs and clad with zirconium which was bonded to the core. The 0,010-in, hole drilled in the cladding is visible in Figure 5. The number $s$ at the bottom of each frame represent the respective times, in tenths of minutes, the specimen had been in contact with $600 \mathrm{~F}$ water. The progress of the corrosion is easily followed from the swelling and subsequent cracking and bursting open of the cladding. Bubbles of hydrogen are visible in some of the pictures, although the progress of any one bubble can rarely be traced on the film because of the time interval between frames.

Figure 6 is a graph plotted to show the manner in which the amount of hydrogen evolved may be obtained. The calibration curve shows the pressure history inside the test vessel when it is filled with $600 \mathrm{~F}$ water with no specimen in place. This is necessary since it takes a finite length of time for pressure equilibrium to be reached (in this case, about $40 \mathrm{~min}$ ). The difference in pressure between a test with a specimen in place and a test without is, therefore, attributable to evolved gas. Of course, allowance must be made for the hydrogen which dissolves in the water and that which is lost by 


\section{$\frac{\text { CONFIDENTIAL }}{15}$}
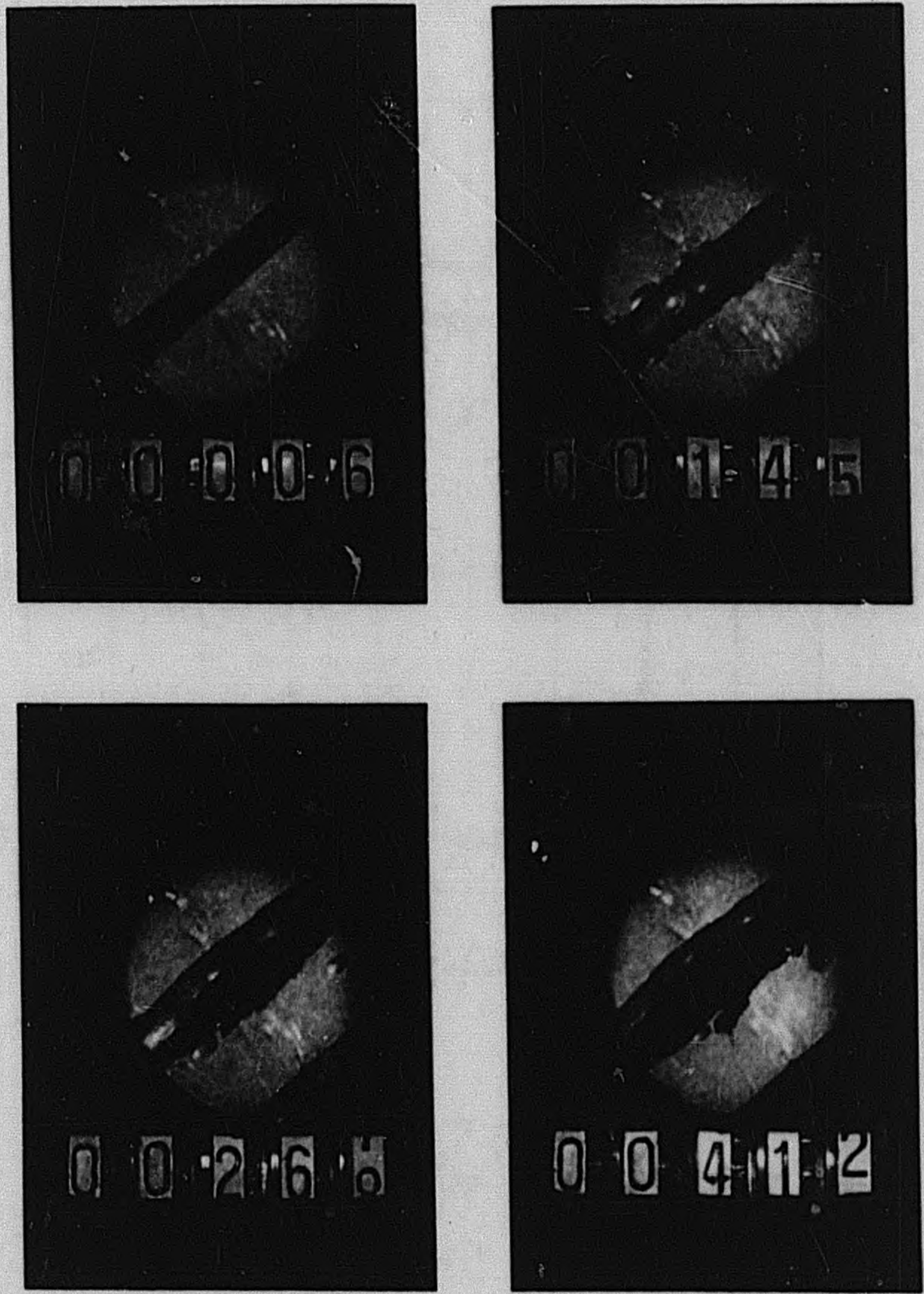

FIGURE 5. REPRESENTATIVE REPRODUCTIONS FROM FILMS OF TEST

CONFIDENTIAL

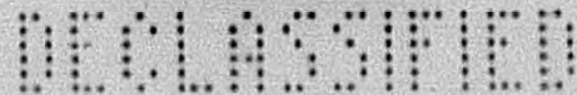




\section{CONFIDENTIAL}

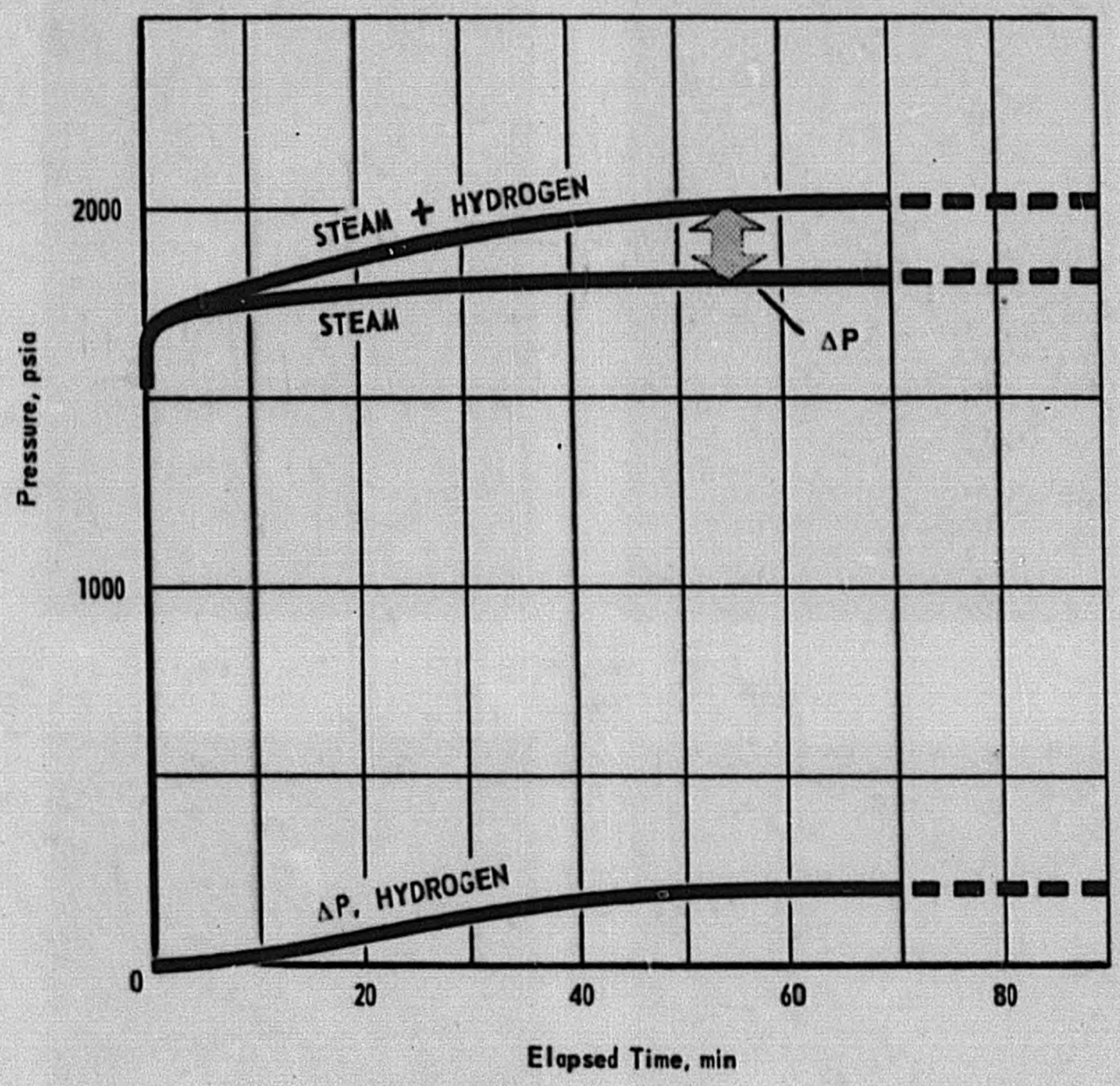

FIGURE 6. TYPICAL PLOT, PRESSURES VERSUS TIME 


\section{CONFIDENTIAL}

17

diffusion through the walls of the test vessel. By the use of suitable geometric equations which relate the area open to attack to the volume of material corroded, the hydrogen-evolution rate may then be translated to a corrosion rate.

This method has been employed to obtain the corrosion rates listed in Table 1. A comparison has been made in Figure 7 of the data in Table 1 with data reported at lower temperatures in several literature sources. In view of the meager data for the 5 and $10 \mathrm{w} / 0$ zirconium-uranium alloys, the lines drawn for these are for rough comparison purposes only. The zero $w / 0$ zirconium line is the one given in CT-3055, which has the equation:

$$
\log _{10} k\left(\mathrm{mg} \mathrm{cm}^{-2} \mathrm{hr}^{-1}\right)=-\frac{6710}{T(\cdot R)}+10.34 \text {. }
$$

It is interesting to note that, in spite of the fairly extensive extrapolation required, the Battelle data lie fairly close to this line.

TABLE 1. SUMMARY OF CORROSION DATA

\begin{tabular}{lccc}
\hline \hline $\begin{array}{c}\text { Bonding } \\
\text { Condition }\end{array}$ & $\begin{array}{c}\text { Zirconium } \\
\text { Content, } \\
\text { w/o }\end{array}$ & $\begin{array}{c}\text { Temperature, } \\
\mathrm{F}\end{array}$ & $\begin{array}{c}\text { Corrosion Rate (k), } \\
\mathrm{mg} /(\mathrm{cm})(\mathrm{hr})\end{array}$ \\
\hline Unclad & 0 & 587 & 6260 \\
Unbonded & 0 & 582 & 4910 \\
Unclad & 5 & 587 & 3150 \\
Unbonded & 5 & 612 & 6300 \\
Unclad & 10 & 602 & 2310 \\
\hline \hline
\end{tabular}

\section{DISCUSSION}

Clarity of detail in the pictures is limited primarily by the grain size in the film and the intensity of the illumination. In the tests made thus far, Type Kodakrome A film has been used, and even though the grain size is not as small as obtainable with Super $\mathrm{XX}$, it was felt that the identification of

\section{CONFIDENTLAL}

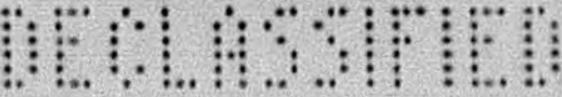




\section{$\frac{\text { CONFIDENTIAL }}{18}$}

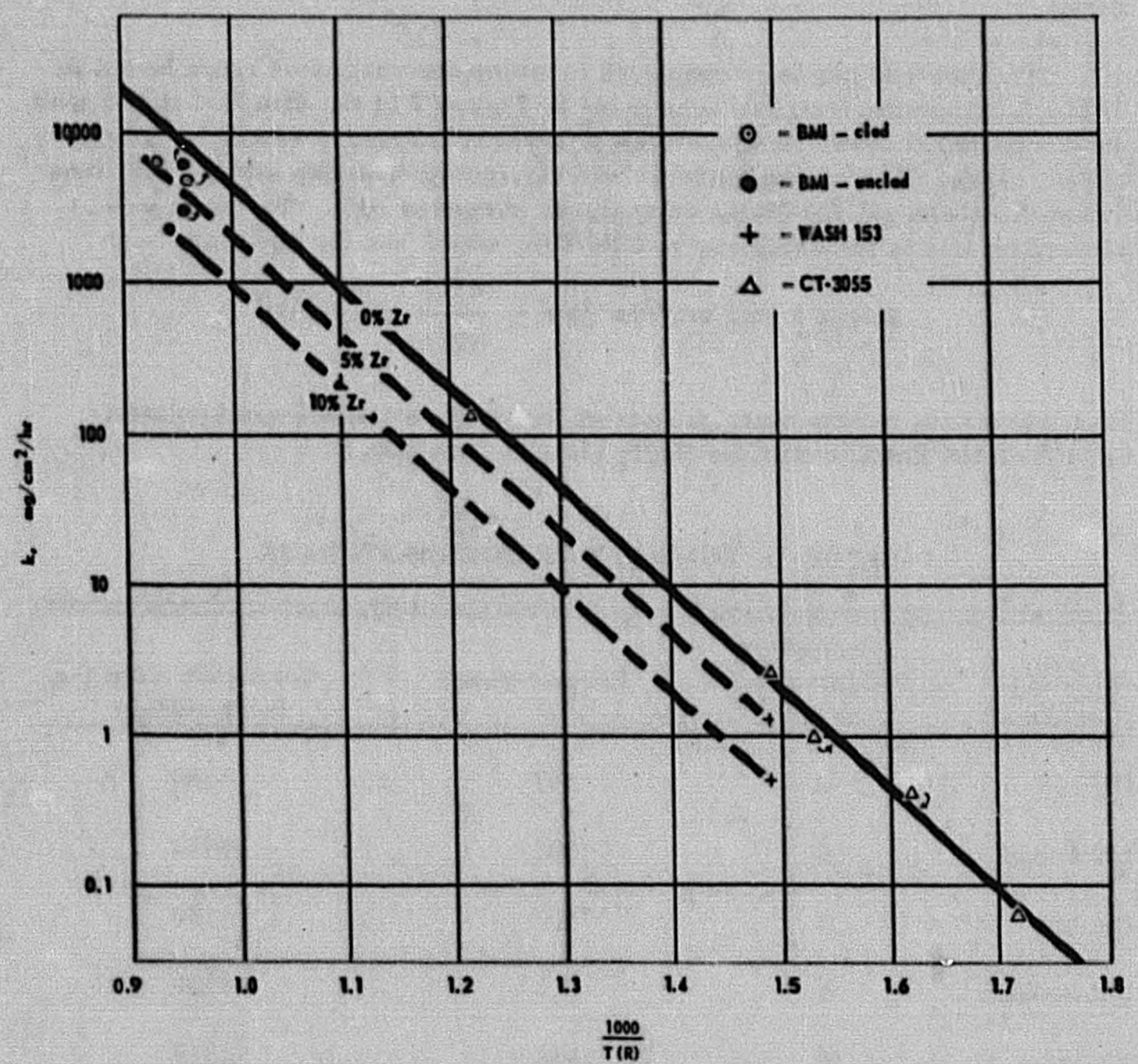

FIGURE 7. CORROSION RATE OF URANIUM-ZIRCONIUM CORE ALLOYS 


\section{CONFIDENTIAL}

19 and 20

color would compensate for the lack of definition, and at the same time show up any characteristic color of the reaction products.

Thus far, the accuracy of the calculated corrosion rates, based on hydrogen-evolution data, is no better than 20 per cent, owing largely to the extreme sensitivity of steam pressure to small changes in temperature. This could be improved by substantially more precise control of steam temperature. In any event, the windowed autoclave affords a relative evaluation of the influence of such variables as core geometry, core alloying, cladding, type of bonding, water temperature, and water impurities on corrosion rate. The most important advantage of this instrument is, however, that it provides a pictorial representation of the corrosion phenomenon while it is occurring. Thus, studies with this tool should add considerably to a better understanding of the effects of clad defects in reactor fuel elements.

\section{DRG:EMS/ks}
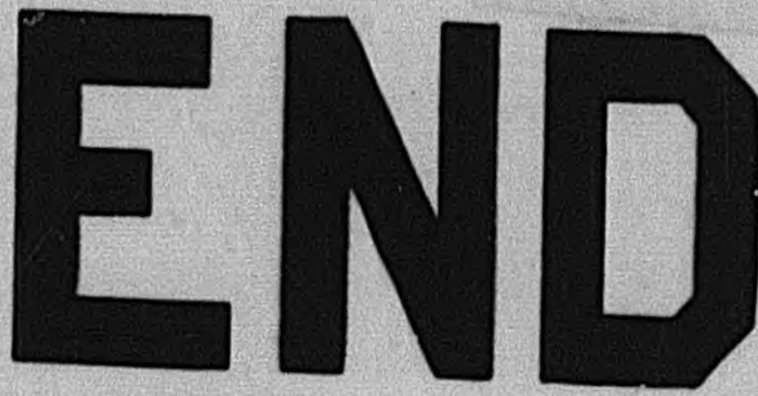

\section{CONFIDENTIAL}

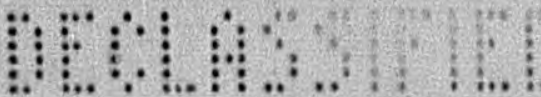

